Review

\title{
p-Akt as a potential poor prognostic factor for gastric cancer: a systematic review and meta-analysis
}

\author{
Fang Cao ${ }^{1, *}$, Cong Zhang ${ }^{2, *}$, Wei Han ${ }^{1}$, Xiao-Jiao Gao ${ }^{3}$, Jun Ma ${ }^{4}$, Yong-Wei Hu${ }^{1}$, Xing \\ $\mathbf{G u}^{5}$, Hou-Zhong Ding ${ }^{1}$, Li-Xia Zhu ${ }^{5}$ and Qin Liu ${ }^{5}$ \\ ${ }^{1}$ Department of General Surgery, Kunshan First People's Hospital Affiliated to Jiangsu University, Kunshan, Jiangsu 215300, \\ P.R. China \\ ${ }^{2}$ Department of Pharmacy, Kunshan Hospital of TCM, Kunshan, Jiangsu 215300, P.R. China \\ ${ }^{3}$ Department of Pathology, Kunshan First People's Hospital Affiliated to Jiangsu University, Kunshan, Jiangsu 215300, P.R. \\ China \\ ${ }^{4}$ Department of Urological Surgery, Kunshan Hospital of TCM, Kunshan, Jiangsu 215300, P.R. China \\ ${ }^{5}$ Department of Gynaecology and Obstetrics, Kunshan First People's Hospital Affiliated to Jiangsu University, Kunshan, \\ Jiangsu 215300, P.R. China \\ *These authors have contributed equally to this work \\ Correspondence to: Wei Han, email: hans64@126.com
}

Keywords: p-Akt, gastric cancer, prognosis, survival, meta-analysis

Received: January 04, $2017 \quad$ Accepted: March 17, $2017 \quad$ Published: April 10, 2017

Copyright: Cao et al. This is an open-access article distributed under the terms of the Creative Commons Attribution License 3.0 (CC BY 3.0), which permits unrestricted use, distribution, and reproduction in any medium, provided the original author and source are credited.

\section{ABSTRACT}

To understand the relationship between p-Akt expression and the prognosis of patients with gastric cancer, we searched six databases, Pubmed, EMBASE, Cochrane Library, CNKI, Wanfang and CBM for relevant articles in order to conduct this metaanalysis. The pooled hazard ratios and corresponding $95 \% \mathrm{CI}$ of overall survival were calculated to evaluate the prognostic value of p-Akt expression in patients with gastric cancer. With 2261 patients combined from 13 available studies, the pooled HR showed a poor prognosis in patients with gastric cancer in the univariate analysis $(H R=1.88$, 95\%CI:1.45-2.43, P<0.00001), and the group "univariate analysis+estimate" ( $H R=1.41,95 \% C I: 1.01-1.97, P=0.04)$, but not in multivariate analysis $(H R=0.66$, 95\%CI: 0.29-1.52, $P=0.33$ ) and estimate ( $H R=1.13,95 \% C I: 0.65-1.95, P=0.67)$. In conclusion, our results indicated that p-Akt was likely to be an indicator of poor prognosis in patients with gastric cancer.

\section{INTRODUCTION}

Gastric cancer, as one of the most dangerous diseases, has claimed countless lives in our accelerated society [1]. Although numerous markers implicated in gastric cancer have been identified, the prognosis remains to be dismal mainly due to marked heterogeneity in histologic characteristics and biological features [2]. In addition, patients at the same condition, such as histological grade, lymph node status and TNM staging, may have dissimilar clinical outcomes [3]. As a result, it is urgent to develop new reliable prognostic markers for patients with gastric cancer.
Akt, or protein kinase $\mathrm{B}$, one of key proteins in the Akt/PI3K/PTEN signaling pathway, is a Serine/Threonine protein kinase that, once activated by phosphorylation, plays an important role in the process of malignant transformation [4]. Phosphorylated Akt (p-Akt) was implicated in inducing signals to interfere with the cell apoptosis, and promoting abilities of proliferation and motility through a crucial mechanism, the activation of mTOR (mammalian target of rapamycin) $[4,5,6]$. Overexpressed p-Akt was considered as an indicator of poor prognosis in many malignancies. For example, a recent meta-analysis reported that high p-Akt expression was significantly associated with worse overall survival in patients with breast cancer (HR=1.52, 95\% CI:1.29- 
1.78, $\mathrm{P}=0.001$ ) [7]. This prognostic value were also showed in another two meta-analyses which summarized a same conclusion that elevated p-Akt expression was related to poor survival in patients with non-small cell lung cancer $[8,9]$.

In gastric cancer, many trials also showed a negative relationship between p-Akt expression and survival. However, some studies failed to detect a significant relationship, and some even obtained a positive one. In particular, several trials gained contradictory results through univariate and multivariate analyses. Furthermore, there were no systematic reviews with meta-analysis about the prognostic value of $\mathrm{p}$-Akt in gastric cancer.

In light of the outstanding controversy of p-Akt, we launched a systematic review of available studies with meta-analysis to evaluate the prognostic value of $\mathrm{p}$-Akt in patients with gastric cancer.

\section{RESULTS}

\section{Search results}

As shown in Figure 1, a total of 2727 articles were retrieved in the initial search. In addition, 31 records were yielded by manual searching. After removing 264 duplicated studies, we read the titles and abstracts of the 2494 studies left, and then, excluded 2356 citations, leaving 138 studies for further full-text review. After punctiliously reading, 125 studies were excluded: 121 studies, including reviews or letters, were excluded for no or insufficient survival data;

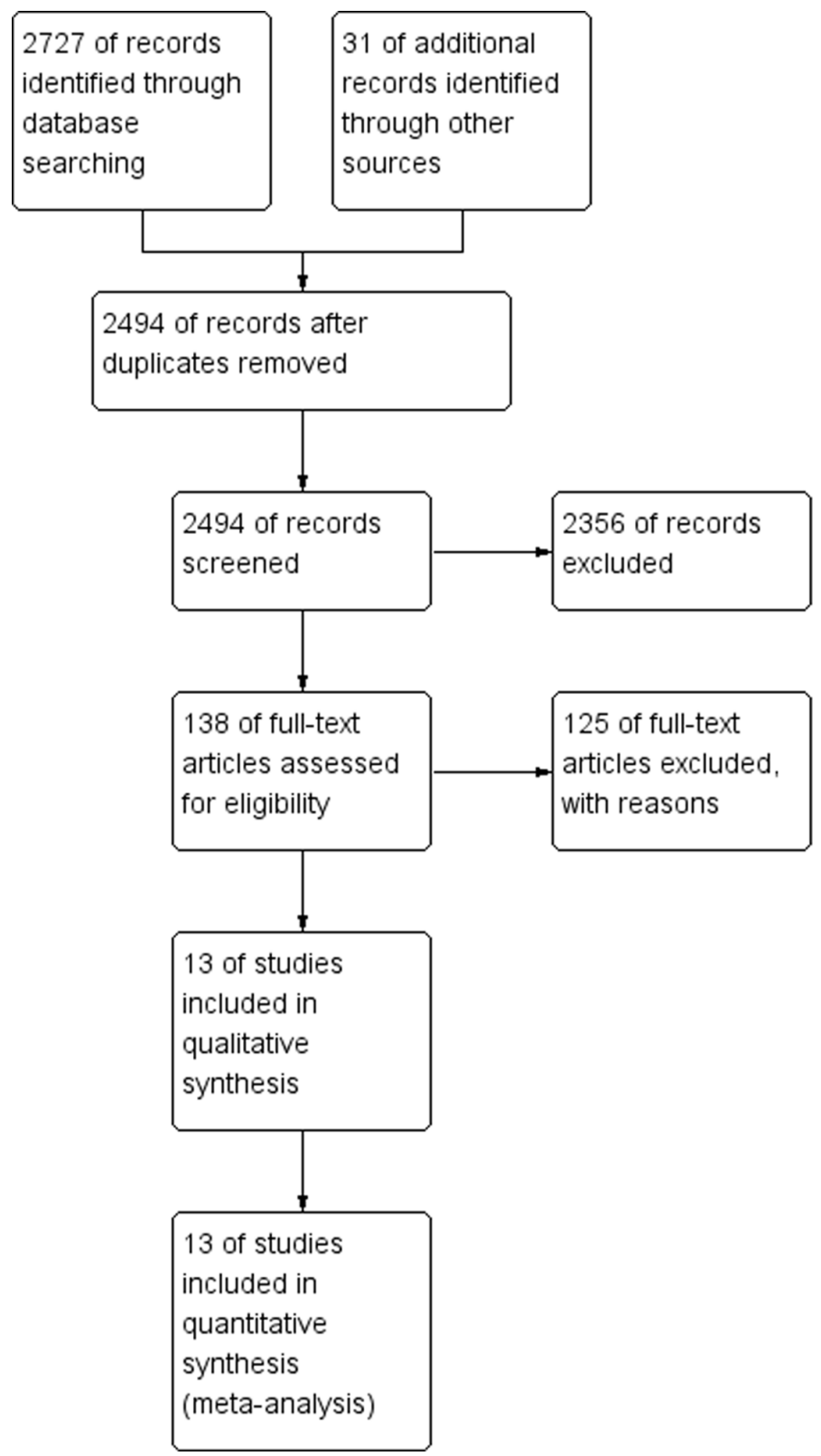

Figure 1: Flow chart for the selection of records to include. 
Table 1: Characteristics of included studies

\begin{tabular}{|c|c|c|c|c|c|c|c|c|c|}
\hline $\begin{array}{l}\text { First } \\
\text { author }\end{array}$ & Year & Region & Sample & $\begin{array}{c}\text { Measure } \\
\text { method }\end{array}$ & Age (years) & N. of $M / F$ & $\begin{array}{l}\text { Primary } \\
\text { antibody }\end{array}$ & Treatment & Follow-up \\
\hline Bian & 2015 & China & Tissue & $\mathrm{IHC}$ & NR & NR & Rabbit Ab & Surgery & $\begin{array}{c}\text { Median } 49 \text { months } \\
\text { (2-80months) }\end{array}$ \\
\hline Chang & 2015 & Korea & Tissue & $\mathrm{IHC}$ & $\begin{array}{l}\text { Mean } 58.1 \\
\text { Median } 61\end{array}$ & $285 / 139$ & Rabbit pAb & Surgery & $\begin{array}{l}\text { Mean } 82.3 \text { months; } \\
\text { Median96.1months } \\
\text { (1-131 months) }\end{array}$ \\
\hline Cinti & 2008 & Italy & Tissue & $\mathrm{IHC}$ & 34-83years & $16 / 34$ & $\mathrm{mAb}$ & Surgery & at least 5 years \\
\hline Han & 2011 & China & Tissue & $\mathrm{IHC}$ & Median 53 & $85 / 23$ & Rabbit pAb & $\begin{array}{c}\text { Surgery } \\
\text { Chemotherapy }\end{array}$ & About 5 years \\
\hline Kobayashia & 2006 & Japan & Tissue & $\mathrm{IHC}$ & NR & NR & Rabbit pAb & Surgery & $>40$ months \\
\hline Liang & 2015 & China & Tissue & $\mathrm{IHC}$ & NR & NR & $\mathrm{mAb}$ & Surgery & $>5$ years \\
\hline Luber & 2011 & Europe & Tissue & $\mathrm{IHC}$ & Median 63 & $30 / 9$ & Mouse mAb & Chemotherapy & Median 379 days \\
\hline Murakami & 2007 & Japan & Tissue & $\mathrm{IHC}$ & Mean 70.8 & $84 / 56$ & Mouse pAb & $\begin{array}{c}\text { Surgery } \\
\text { Chemotherapy }\end{array}$ & at least 5 years \\
\hline Murayama & 2009 & Japan & Tissue & $\mathrm{IHC}$ & Median 65 & $77 / 32$ & Rabbit pAb & Surgery & $\begin{array}{l}\text { Median } 1953 \text { days } \\
\text { (50-3197 days) }\end{array}$ \\
\hline Nam & 2003 & Korea & Tissue & $\mathrm{IHC}$ & Mean 54.8 & $210 / 101$ & NR & Surgery & $\begin{array}{l}\text { Mean } 54 \text { months } \\
\text { (1-72 months) }\end{array}$ \\
\hline Sasaki & 2014 & Japan & Tissue & Immunoblot & NR & NR & NR & Surgery & $>5$ years \\
\hline Sukawa & 2012 & Japan & Tissue & $\mathrm{IHC}$ & Median 71 & $157 / 74$ & $\mathrm{pAb}$ & Surgery & About 10 years \\
\hline Xue & 2012 & China & Tissue & $\mathrm{IHC}$ & Median65.5 & $158 / 71$ & Mouse $\mathrm{pAb}$ & Surgery & $>5$ years \\
\hline
\end{tabular}

N.of P.: the number of patients; M/F: male/female; mAb: monoclonal antibody; pAb: polyclonal antibody; NR: not reported.

and four studies [10-13] were removed because they only investigated Akt expression, but not p-Akt. Therefore, 13 eligible studies [14-26] with 2261 patients in total, were enrolled finally in this meta analysis.

\section{Study characteristics}

The basic characteristics and results of the 13 eligible studies were summarized in Table 1 and Table 2. Briefly, 11 studies were conducted in Asian populations, while the remaining used Caucasian populations [16, 20]; study sample sizes ranged from 28 to 424; all of the cohorts were treated with surgery, except one treated only with chemotherapy [20], and the treatment of another two studies was a combined regimen of surgery plus chemotherapy $[17,21]$; p-Akt expression was detected in the cytoplasm or nucleus of the tissues in all the studies, with rabbit or mouse antibodies, and polyclonal or monoclonal antibodies, but two studies [23, 24] didn't reported what kind of p-Akt they used; the cut-offs were identified by the extent or intensity, but the cut-off values of p-Akt varied in each study. Seven of them selected a moderate value, such as $50 \%$, score $3 / 6$ and the median level, and five chose " $>10 \%$ " according to the extent of the staining. However, the left one, "Murakami 2007 ", considered the staining $>1 \%$ as a positive value. Among all of them, five reported that high level of p-Akt expression was related to poor survival; and six revealed no significant impact on survival. However, two reported p-Akt as an indicator of good prognosis. Ten of these thirteen cohorts reported the relationship between p-Akt expression and overall survival. Among them, four gave a HR directly from univariate analysis, and another six only presented Kaplan-Meier survival curves with or without multivariate HRs. So, we estimated HRs from these six K-M curves.

\section{Quality assessment}

The study quality scores based on the NOS, ranged from 6 to 8, with a mean of 6.85 . None of these thirteen studies obtained a NOS $\leq 5$, indicating that all of them had high levels of methodological quality in our meta-analysis (Table 3).

\section{p-Akt expression and survival outcome}

16 results, obtained from ten trials with OS, were divided into three groups, univariate, multivariate and estimate, by which three pooling HRs were produced $(\mathrm{HR}=1.88,95 \% \mathrm{CI}: 1.45-2.43, \mathrm{P}<0.00001 ; \mathrm{HR}=0.66$, 95\%CI: $0.29-1.52, \mathrm{P}=0.33$; and $\mathrm{HR}=1.13,95 \% \mathrm{CI}: 0.65$ $1.95, \mathrm{P}=0.67$, respectively. Figure 2 ). However, only the group, univariate, with a $\mathrm{I}^{2}=0 \%$, had no heterogeneity. Then, we combined the two groups, univariate and estimate, and figured out a new incorporative HR 
Table 2: Characteristics of included studies

\begin{tabular}{|c|c|c|c|c|c|c|c|c|c|}
\hline First author & Year & N. of $P$. & Location & $\begin{array}{l}\text { Scoring } \\
\text { method }\end{array}$ & $\begin{array}{l}\text { Cut-off of p-Akt } \\
\text { high expression }\end{array}$ & Outcome & Obtainment & HR & $95 \% \mathrm{CI}$ \\
\hline \multirow[t]{4}{*}{ Bian } & 2015 & 396 & $\mathrm{C}$ & EI & Score 3-6 & OS & $\mathrm{U}$ & 1.931 & $1.379-2.703$ \\
\hline & & & & & & OS & M & 1.332 & $0.943-1.882$ \\
\hline & & & & & & RFS & $\mathrm{U}$ & 1.537 & $1.074-2.199$ \\
\hline & & & & & & RFS & M & 1.221 & $0.847-1.762$ \\
\hline Chang & 2015 & 424 & $\mathrm{C}$ & EI & $\begin{array}{l}>50 \% \text { or moderate } \\
\text { to strong intensity }\end{array}$ & DSS & M & 0.724 & $0.485-1.083$ \\
\hline Cinti & 2008 & 50 & $\mathrm{C}$ & E & $>10 \%$ & RFS & K-M & 3.04 & $1.18-7.85$ \\
\hline Han & 2011 & 108 & $\mathrm{CN}$ & EI & Score $>6$ & DFS & K-M & 1.67 & $0.86-3.24$ \\
\hline Kobayashia & 2006 & 88 & $\mathrm{C}$ & E & $>50 \%$ & OS & K-M & 2.16 & $0.86-5.43$ \\
\hline \multirow[t]{2}{*}{ Liang } & 2015 & 107 & $\mathrm{C}$ & EI & Score $>1.5$ & OS & K-M & 1.78 & $1.09-2.91$ \\
\hline & & & & & & DFS & K-M & 1.76 & $1.02-3.04$ \\
\hline \multirow[t]{2}{*}{ Luber } & 2011 & 28 & $\mathrm{~N}$ & E & $>10 \%$ & OS & $\mathrm{U}$ & 1.1 & $0.2-4.8$ \\
\hline & & & & & & TTP & $\mathrm{U}$ & 0.5 & $0.1-1.5$ \\
\hline \multirow[t]{2}{*}{ Murakami } & 2007 & 140 & $\mathrm{CN}$ & E & $>1 \%$ & OS & $\mathrm{M}$ & 0.227 & $0.119-0.433$ \\
\hline & & & & & & OS & $\mathrm{K}-\mathrm{M}$ & 1.63 & $0.64-4.10$ \\
\hline \multirow[t]{4}{*}{ Murayama } & 2009 & 109 & $\mathrm{C}$ & EI & $\begin{array}{l}>10 \% \text { or strongly } \\
\text { stained }\end{array}$ & OS & M & 0.35 & $0.11-1.16$ \\
\hline & & & & & & OS & K-M & 0.16 & $0.04-0.64$ \\
\hline & & & $\mathrm{N}$ & & & OS & $\mathrm{M}$ & 1.787 & $0.80-3.99$ \\
\hline & & & $\mathrm{CN}$ & & & OS & K-M & 1.36 & $0.34-5.48$ \\
\hline Nam & 2003 & 311 & $\mathrm{C}$ & E & Moderate to strong & OS & K-M & 0.46 & $0.23-0.92$ \\
\hline \multirow[t]{2}{*}{ Sasaki } & 2014 & 40 & $\mathrm{CN}$ & $\mathrm{E}$ & $\begin{array}{l}\text { Median of the } \\
\text { protein level }\end{array}$ & OS & $\mathrm{U}$ & 2.453 & $0.945-6.368$ \\
\hline & & & & & & OS & M & 0.572 & $0.236-1.389$ \\
\hline Sukawa & 2012 & 231 & $\mathrm{CN}$ & $\mathrm{E}$ & $>10 \%$ & OS & $\mathrm{U}$ & 1.75 & $1.12-2.80$ \\
\hline Xue & 2012 & 229 & $\mathrm{CN}$ & E & $>10 \%$ & OS & K-M & 1.73 & $1.16-2.59$ \\
\hline
\end{tabular}

N. of P.: the number of patients; C: cytoplasm; N: nucleus; CN: cytoplasm and nucleus; OS: overall survival; DFS: diseasefree survival; DSS: disease-specific survival; TTP: time to progression; RFS: recurrence-free survival; HR: hazard ratio; "M": the multivariate analysis; "U": the univariate analysis; "K-M": Kaplan-Meier survival curves; "E": identifying the cut-off by the extent; "I": identifying the cut-off by the intensity; "EI": both by the extent and the intensity.

being 1.41 (95\%CI: 1.01-1.97, $\mathrm{P}=0.04$, Figure 2D). Though with highly significant heterogeneity $\left(\mathrm{I}^{2}=62 \%\right.$, $\mathrm{Ph}=0.004)$, this new result also had significance in statistics, illustrating that high p-Akt expression was significantly associated with poor OS of patients with gastric cancer.

We also calculated the pooled HRs of DFS and RFS, and obtained statistically significant estimates ( $\mathrm{HR}=1.72$, 95\%CI: 1.13-2.63, $\mathrm{P}=0.01$; and $\mathrm{HR}=1.67,95 \% \mathrm{CI}: 1.20$ $2.34, \mathrm{P}=0.003$, respectively), showing elevated $\mathrm{p}$-Akt expression associated with poor prognosis. However, we failed to obtain more pooling HRs of other survival outcomes.

\section{Subgroup analyses}

Due to the heterogeneity, we performed the subgroup analyses, presented in Table 4, by stratifying the combined data according to location ( $\mathrm{C}$ vs. $\mathrm{N}$ vs. $\mathrm{CN}$ ), main treatment (surgical vs. non-surgical), study region (Asian vs. Caucasian), sample size ( $<100$ vs. $\geqq 100$ ), obtainment (univariate vs. estimate), scoring method (E vs. EI), cut-off (1\% vs. 10\% vs. Moderate), measure method (IHC vs. Immunoblot) and primary antibody (Rabbit vs. Mouse vs. pAb vs. mAb vs. NR). Because of too few cohorts in multivariate analysis, and no heterogeneity in univariate analysis, we conducted the 
Table 3: Quality assessment of eligible studies with Newcastle-Ottawa Scale

\begin{tabular}{|c|c|c|c|c|c|}
\hline First author & Year & NOS & Selection & Comparability & Outcome \\
\hline Bian & 2015 & 6 & $\star \star \star *$ & $\star$ & $\star \star *$ \\
\hline Chang & 2015 & 8 & $\star \star \star$ & $\star \star$ & $\star \star \star$ \\
\hline Cinti & 2008 & 7 & $\star \star \star$ & $\star \star$ & $\star \star$ \\
\hline Han & 2011 & 7 & $\star \star \star *$ & $\star *$ & $\star \star \star$ \\
\hline Kobayashia & 2006 & 6 & $\star \star \star$ & $\star$ & $\star \star *$ \\
\hline Liang & 2015 & 6 & $\star \star *$ & $\star \star *$ & $\star \star *$ \\
\hline Luber & 2011 & 7 & $\star \star \star$ & $\star$ & $\star \star \star *$ \\
\hline Murakami & 2007 & 8 & $\star \star \star$ & $\star \star$ & $\star \star \star *$ \\
\hline Murayama & 2009 & 8 & $\star \star \star$ & $\star \star *$ & $\star \star \star$ \\
\hline Nam & 2003 & 6 & $\star \star \star *$ & $\star \star$ & $\star *$ \\
\hline Sasaki & 2014 & 7 & $\star \star$ & $\star \star$ & $\star \star \star *$ \\
\hline Sukawa & 2012 & 7 & $\star \star \star *$ & $\star$ & $\star \star \star *$ \\
\hline Xue & 2012 & 6 & $\star \star \star$ & $\star *$ & $\star \star$ \\
\hline
\end{tabular}

*The score was produced by discussion.

subgroup analyses only in the combination of univariate analysis and estimate, called "U+E", and we failed to get any potential source of heterogeneity in " $U+E$ ".

\section{p-Akt expression and clinicopathological features}

In our study, we also assessed the relationship of p-Akt expression with pathological differentiation, $\mathrm{N}$ status and tumor staging. In spite of no significant difference between p-Akt expression and pathological differentiation, we found that high p-Akt expression was associated with lymph node metastasis and advanced gastric cancer (for pathological differentiation, $\mathrm{HR}=1.17$, 95\%CI: 0.94-1.46, $\mathrm{P}=0.15$; for $\mathrm{N}$ status, $\mathrm{HR}=1.34,95 \% \mathrm{CI}$ : 1.11-1.62, $\mathrm{P}=0.003$; and for tumor staging, $\mathrm{HR}=1.60$, $95 \%$ CI: $1.27-2.02, \mathrm{P}<0.0001)$.

\section{Sensitivity analyses}

By using sensitivity analysis, we deleted an individual result at a time and pooled the others into a new HR to compare with the previous one, and all studies of this meta-analysis were assessed to value the stability of our results. Pooled results for "univariate", "multivariate" and "estimate" were insensitive to the removal of individual studies, and the corresponding combined HRs were not substantially changed (data not shown, Figure 3).

\section{Publication bias}

We conducted the publication bias assessment of the thirteen studies by funnel plots and Egger's test. No obvious asymmetry was found in all of the three groups (Figure 4), and results of Egger's test also suggested no evidence of publication bias in "univariate", "multivariate" and "estimate" $(\mathrm{P}=0.752, \mathrm{P}=0.367$ and $\mathrm{P}=0.278$, respectively).

\section{DISCUSSION}

p-Akt, as a potential biomarker of poor prognosis in various malignant tumors, has aroused prominent interest in this critical period of high morbidity and mortality of neoplasms. Although some studies failed to find any significance of the relationship between p-Akt expression and survival, all of these three meta-analyses proved that over-expression of p-Akt was correlated with an unfavorable outcome in carcinomas [7, 8, 9]. In spite of small sample sizes and controversial reports, many studies have investigated the prognostic value of p-Akt in gastric cancer. Furthermore, no meta-analyses have previously been conducted on the prognostic value of p-Akt in gastric cancer. Hence, we performed this meta-analysis to clarify this question and explore its prognostic value in gastric cancer.

To the best of our knowledge, the present metaanalysis, including a total of 13 studies with 2261 patients, was the first meta-analysis systematically evaluating the prognostic value of p-Akt in patients with gastric cancer, and showed that over-expressed p-Akt was a strong predictor of inferior overall survival in the univariate analysis in patients with gastric cancer. Though without any significance in multivariate analysis and estimated $\mathrm{K}-\mathrm{M}$ curves, a poor prognosis associated with high p-Akt expression could be found in the group, "U+E", which we pooled results obtained from studies in the group of univariate analysis, and those in the group of estimate. Because those estimates calculated form curves 
was univariate, but not multivariate, we also figured out estimates from K-M curves of studies only with multivariate analysis [8]. In our following sensitivity analysis, no substantial changes were found, and another strength of this meta-analysis was that no publication biases were detected, indicating that our combined results may be unbiased. In our study, we also found that high p-Akt expression was correlated with lymph node metastasis and advanced gastric cancer.

Many molecular mechanisms, associated with the alteration of $\mathrm{p}$-Akt expression in malignancies, have been explored out. In a total of 202 gastric cancer patients, Hisamatsu demonstrated that there was a positive relationship between p-Akt and EGFR, both of which were significantly correlated with DNA aneuploidy [27]. The signaling pathway, Akt/PI3K/PTEN/mTOR, was related to the pathogenic process of several neoplastic diseases $[28,29]$, and the activation of this signaling pathway was also associated with poor survival in solid tumors [30]. Many molecular biomarkers, such as SPARC, ZIC1 and NM23-H1, were up-regulated or down-regulated through the Akt/PI3K/PTEN/mTOR signaling pathway, and

A.

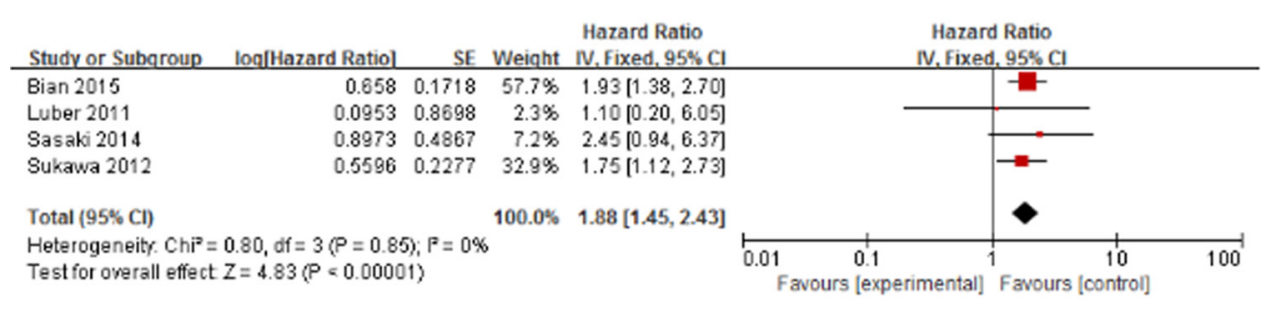

B.

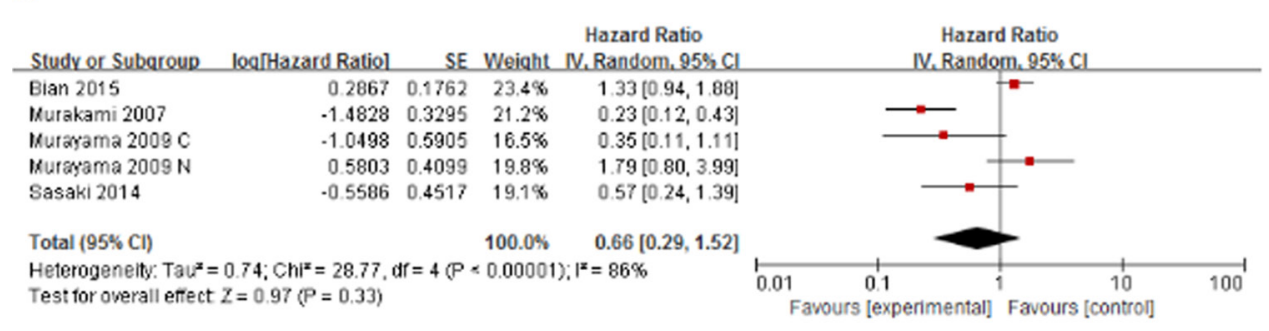

C.

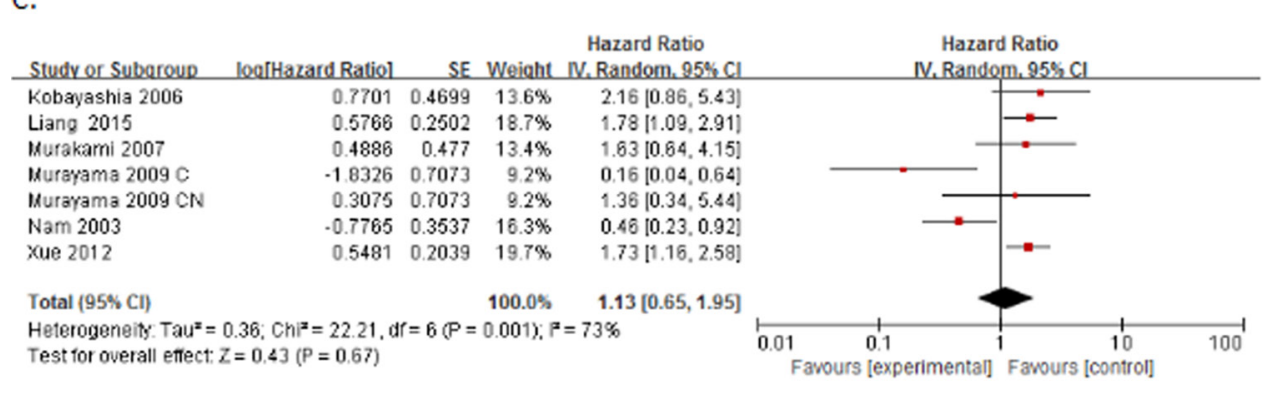

D.

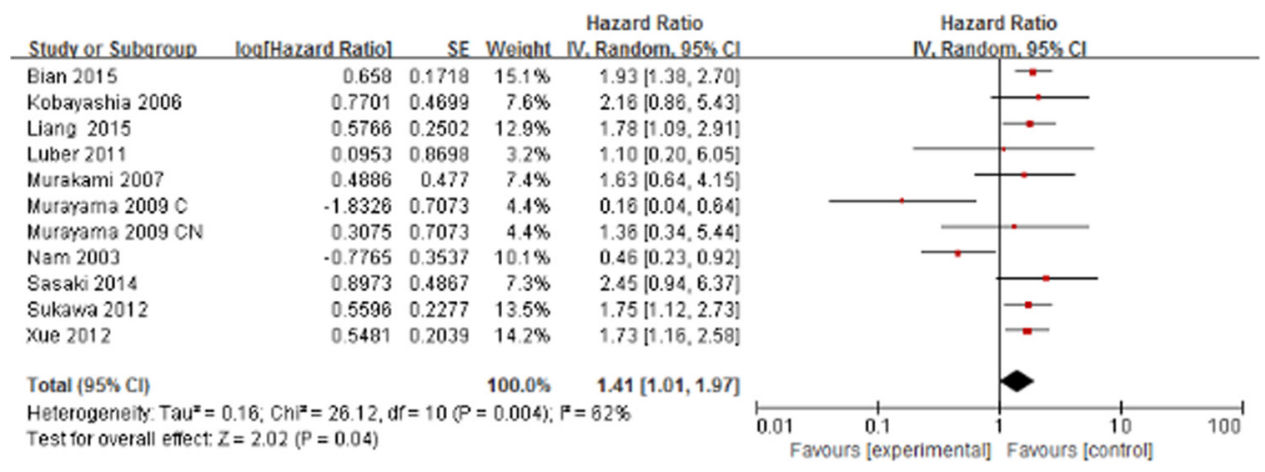

Figure 2: Forest plot of hazard ratios (HRs) for OS of high p-Akt expression versus low expression in gastric cancer. (A) The HRs for OS in univariate analysis; (B) the HRs for OS in multivariate analysis; (C) the HRs for OS in estimate; (D) the HRs for OS in univariate analysis and estimate. 
Table 4: Subgroup analyses of the association between high p-Akt expression and overall survival in the group "U+E" of patients with gastric cancer

\begin{tabular}{|c|c|c|c|c|c|c|}
\hline Subgroup & Data sets & Model & HR (95\%CI) & $\mathbf{P}$ & $\mathbf{I}^{2}$ & $\mathbf{P h}$ \\
\hline All & 11 & Random & $1.41[1.01,1.97]$ & 0.04 & $62 \%$ & 0.004 \\
\hline \multicolumn{7}{|l|}{ Location } \\
\hline $\mathrm{C}$ & 5 & Random & $1.04[0.51,2.10]$ & 0.92 & $84 \%$ & $<0.0001$ \\
\hline $\mathrm{N}$ & 1 & - & $1.10[0.20,6.05]$ & 0.91 & - & - \\
\hline $\mathrm{CN}$ & 5 & Fixed & $1.76[1.35,2.30]$ & $<0.0001$ & $0 \%$ & 0.96 \\
\hline \multicolumn{7}{|l|}{ Region } \\
\hline Asian & 10 & Random & $1.42[1.00,2.01]$ & 0.05 & $65 \%$ & 0.002 \\
\hline Caucasian & 1 & - & $1.10[0.20,6.05]$ & 0.91 & - & - \\
\hline \multicolumn{7}{|l|}{ Treatment } \\
\hline Surgical & 10 & Random & $1.42[1.00,2.01]$ & 0.05 & $65 \%$ & 0.002 \\
\hline Non-surgical & 1 & - & $1.10[0.20,6.05]$ & 0.91 & - & - \\
\hline \multicolumn{7}{|l|}{ Sample size } \\
\hline$<100$ & 3 & Fixed & $2.09[1.12,3.87]$ & 0.02 & $0 \%$ & 0.72 \\
\hline$\geqq 100$ & 8 & Random & $1.28[0.86,1.91]$ & 0.22 & $72 \%$ & 0.0009 \\
\hline \multicolumn{7}{|l|}{ Obtainment } \\
\hline univariate & 4 & Fixed & $1.88[1.45,2.43]$ & $<0.00001$ & $0 \%$ & 0.85 \\
\hline estimate & 7 & Random & $1.13[0.65,1.95]$ & 0.67 & $73 \%$ & 0.001 \\
\hline \multicolumn{7}{|c|}{ Scoring method } \\
\hline $\mathrm{E}$ & 7 & Random & $1.46[0.96,2.21]$ & 0.08 & $57 \%$ & 0.03 \\
\hline EI & 4 & Random & $1.21[0.60,2.44]$ & 0.59 & $75 \%$ & 0.008 \\
\hline \multicolumn{7}{|l|}{ Cut-off } \\
\hline $1 \%$ & 1 & - & $1.63[0.64,4.15]$ & 0.31 & - & - \\
\hline $10 \%$ & 5 & Random & $1.19[0.65,2.18]$ & 0.57 & $64 \%$ & 0.03 \\
\hline Moderate & 5 & Random & $1.51[0.89,2.56]$ & 0.13 & $73 \%$ & 0.005 \\
\hline \multicolumn{7}{|c|}{ Measure method } \\
\hline IHC & 10 & Random & $1.35[0.95,1.92]$ & 0.10 & $64 \%$ & 0.003 \\
\hline Immunoblot & 1 & - & $2.45[0.94,6.37]$ & 0.07 & - & - \\
\hline \multicolumn{7}{|l|}{$\begin{array}{l}\text { Primary } \\
\text { antibody }\end{array}$} \\
\hline Rabbit & 4 & Random & $1.13[0.45,2.85]$ & 0.79 & $75 \%$ & 0.007 \\
\hline Mouse & 3 & Fixed & $1.68[1.17,2.41]$ & 0.005 & 0 & 0.88 \\
\hline $\mathrm{pAb}$ & 1 & - & $1.75[1.12,2.73]$ & 0.02 & - & - \\
\hline $\mathrm{mAb}$ & 1 & - & $1.78[1.09,2.91]$ & 0.02 & - & - \\
\hline NR & 2 & Random & $1.03[0.20,5.29]$ & 0.97 & $87 \%$ & 0.005 \\
\hline
\end{tabular}

C: cytoplasm; N: nucleus; CN: cytoplasm and nucleus; U+E: univariate analysis + estimate of Kaplan-Meier survival curves. 
promoted or inhibited the growth of human tumors [3133]. Besides, overexpression of these proteins might also be linked to better or worse survival [34-36]. Moreover, some drugs, such as 5-FU and LY294002, could downregulate the activated p-Akt to overcome intrinsic and acquired resistance of 5-FU in SNU-719 cells, a EBV gastric cancer cell line [37]. Therefore, this pro-oncogenic signal, p-Akt, the prognostic value of which will be more important, especially with respect to Akt/PI3K/PTEN/ mTOR signaling pathway, has become a promising target for the development of drugs.

Admittedly, several limitations were unavoidable in our meta-analysis. Firstly, though with 2261 patients in total, the sample size was still small. The studied patients couldn't reflect the real outcome of whole gastric cancer population and this could cause some selection bias or else. Secondly, despite the HRs estimated from Kaplan-Meier curves were results of univariate analysis, these estimates were inaccurate and might influence our results in the groups, estimate and "U+E". In addition, although many meta-analyses combined HRs whether with univariate analysis or with multivariate analysis, our study considered that HRs with univariate analysis, including estimated from univariate curves, included some confounding factors, but HRs with multivariate analysis precluded these factors, to some degree. Although HRs with multivariate analysis seemed to be better, the capability to eliminate factors of each study must be different. Thus, all groups should be calculated and discussed in our manuscript. Thirdly, Meta-analysis
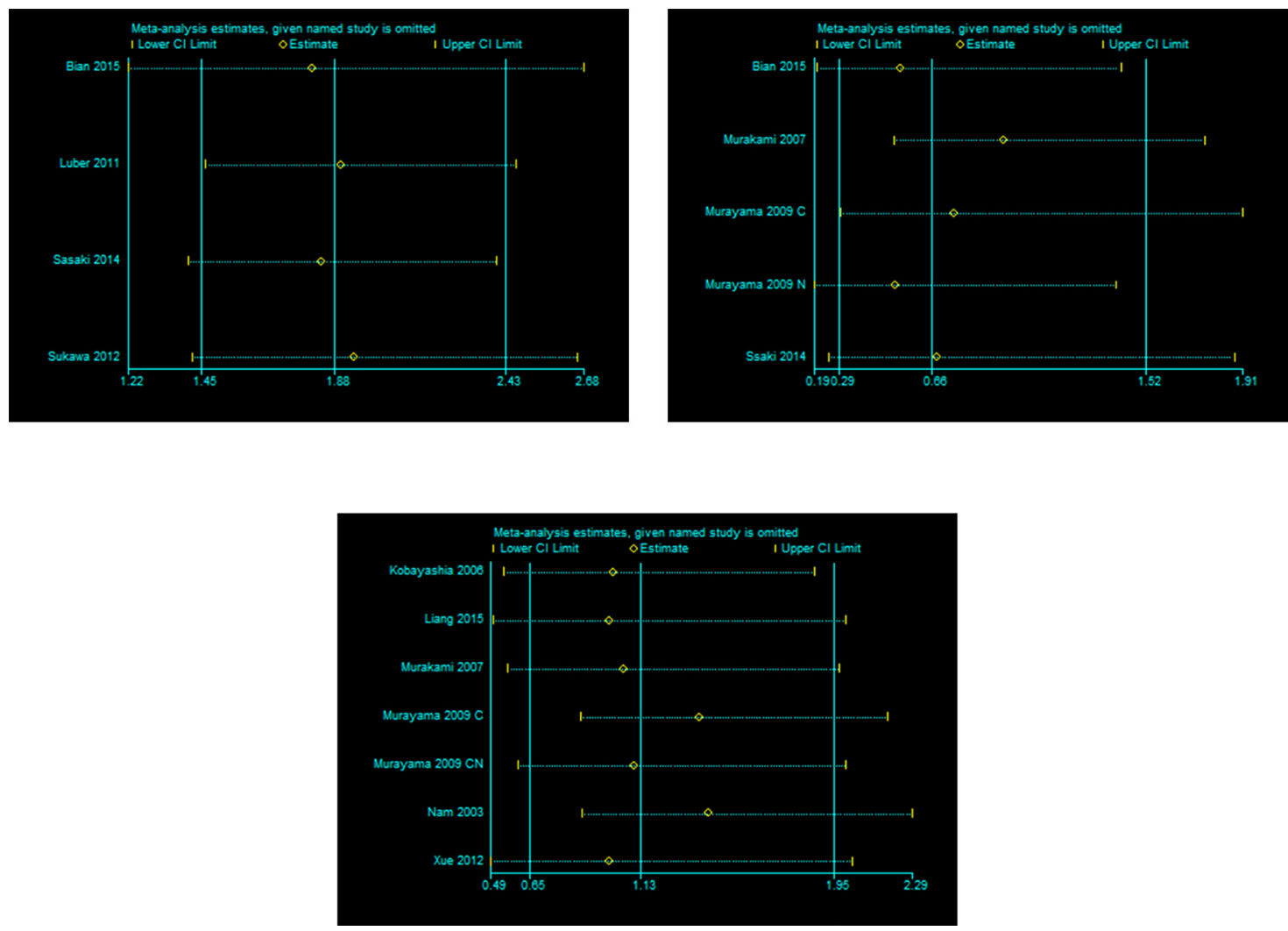

Figure 3: Influence analysis. (A) was about univariate analysis; (B) was about multivariate analysis; (C) was about estimate.
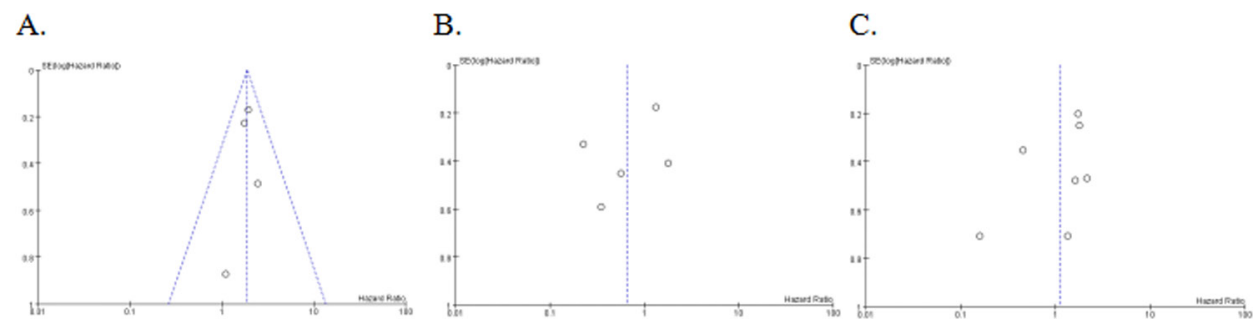

Figure 4: Funnel plot of 10 studies. (A) was about univariate analysis; (B) was about multivariate analysis; (C) was about estimate. 
is an effective method to combine the results of RCT, but recently, this approach has been applied successfully for evaluation of prognostic indicators in patients with malignant diseases. However, these studies investigating genes expression couldn't be designed as RCT, so all studies were non-RCT. Fourthly, although we obtained a significant pooled HR without any heterogeneity when deleting two studies, "Nam 2003" and "Murayama 2009 C", in the sensitivity analysis, we failed to find the potential source of heterogeneity in the subgroup analyses, which meant that various factors might be lumped together. So, some possible sources of heterogeneity might be undetected. Fifthly, in our subgroup analyses, Akt expression seemed to correlate with prognostic outcome only in studies conducted in Asian countries or surgical treatment (only one study conducted in Caucasian and non-surgical treatment). Besides, the cut-offs were various and we divided them into three parts, "> $>1 \% ", ">10 \% "$ and "moderate", but we failed to gain any significant HR, and the heterogeneity was still existent. Thus, the pooling HR combined by results with univariate analysis and results estimated by K-M curves might be unstable, and more researches, with a standard cut-off, on p-Akt expression in gastric cancer should be conducted. In addition, some unpublished studies and negative studies could also be ignored. Because we launch this rigorous search to collect as many studies as possible, and then funnel plots and Egger's test both showed no obvious publication bias in our results, the influence of these studies might be limited. Last but not least, we only searched the studies in English and Chinese. This could lose some available studies in other languages.

In conclusion, the elevated p-Akt expression might be associated with a poor prognosis in patients with gastric cancer. This meta-analysis showed the current status of many inconsistencies and imperfections in researches of p-Akt in gastric cancer. Thus, more rigorous studies should be performed to confirm our conclusion and explore its molecular functions.

\section{MATERIALS AND METHODS}

\section{Publication selection}

We searched Pubmed, EMBASE, Cochrane Library, CNKI (China National Knowledge Infrastructure), Wanfang(Chinese database) and CBM (China Biological Medicine Database) from their incipiency to January, 2016. The key words were used as follow: "Akt", "phospho-Akt", "protein kinase B", "PKB”, "gastric", "stomach", "prognosis" and "survival". Reference lists of reviews and articles were hand-searched for potential articles. Also, manuscripts were manually scrutinized to obtain additional trials most relevant to this review. Only studies published in peer reviewed journals in English or Chinese were included. All the initially identified articles were scanned independently by two reviewers (Fang Cao and Cong Zhang). However, we had no protocol developed for this review.

\section{Inclusion and exclusion criteria}

Inclusion criteria were: (a) clinical trials reported patients with gastric cancer; (b) p-Akt protein expression in the tissue specimens of patients with gastric cancer, was measured with immunohistochemistry (IHC) or immunoblot analysis; (c) studies reported the association between p-Akt expression and survival outcome; (d) studies contained HRs and 95\% CI for OS or other outcomes which either were reported or could be estimated from K-M curves; (e) if the study population was overlapping or duplicated, only the most recent or the most complete report would be enrolled.

Exclusion criteria were: (a) experiment only in vitro or in vivo but not based on patients; (b) literature published as abstracts, letters, reviews, editorials, case reports and expert opinions; (c) studies without HRs and its corresponding 95\% CI about OS, or K-M survival curves; (d) studies only with data about mutations of the Akt gene or only reporting mRNA; (e) similar and repeated studies.

Disagreement was resolved by discussion between two reviewers (Fang Cao and Cong Zhang) or consultation with a third one (Wei Han).

\section{Data extraction and quality assessment}

We extract the following information from each study: (a) general information, including first author, publication year, region of origin, sample size, gender and age of patients, and the follow-up duration; (b) clinical outcomes, including OS or others, with HRs and $95 \%$ CI. If no univariate or unadjusted HR was available, we used a digitizing program, Engauge Digitizer, which could rendered K-M curves into numbers. And then, we put the data into a Tierney table, by which the estimated HR with its corresponding 95\%CI were figured out immediately [38]. This estimate was performed independently by two reviewers (Fang Cao and Cong Zhang), and the disagreement was also resolved by discussion between the two reviewers or consultation with a third reviewer (Wei Han). Note that, despite we obtained univariate unadjusted HRs, multivariate adjusted HRs and estimated HRs, we only combined univariate unadjusted HRs and estimated HRs into a new pooled estimate, rather than the multivariate adjusted HRs [8].

Two independent reviewers (Fang Cao and Cong Zhang) assessed the quality of each study with the Newcastle-Ottawa Quality Assessment Scale (NOS) [39]. This scale, including three parts, selection, comparability and outcome, mainly used in non-RCT studies. We used the quality assessment scale of cohort studies. A study 
with NOS $\geq 6$ was regarded as a high-quality study [40]. Disparity was also resolved by discussion or consultation.

\section{Data synthesis and analysis}

OS (overall survival), associated with p-Akt expression in patients with gastric cancer, was the primary outcome. Other survival outcomes, including DFS (disease-free survival), TSS (tumor-special survival), DSS (disease-specific survival), TTP (time to progression), MFS (metastasis-free survival) and RFS (recurrence-free survival), were also collected. HR with its $95 \%$ CI was used to be the effect measure of interest. Estimates of HRs were weighted and pooled using the Mantel-Haenszel method. A pooled $\mathrm{HR}>1.00$, with its $95 \% \mathrm{CI}$ did not overlap 1, indicated a worse survival for the group with p-Akt expression.

The $\mathrm{Q}$ and $\mathrm{I}^{2}$ test were used to measure the heterogeneity among cohorts. A random or Fixed model was identified by the heterogeneity analysis. A fixed effect model was selected if $\mathrm{I}^{2}<50 \%$; and the random effect model was applied if $\mathrm{I}^{2} \geqq 50 \%$. An $\mathrm{I}^{2}>50 \%$ indicated substantial heterogeneity in studies, and we would perform subgroup analyses to detect potential sources of heterogeneity.

A funnel plot and Egger's linear regression test were used to assess the latent publication bias, and in Egger's test, a value $<0.05$ indicated an inevitable significant publication bias [41].

All the analyses were conducted by STATA statistical software package version 12.0 (STATA12) and Review Manager software version 5.3 (The Cochrane Collaboration, RevMan5.3). All statistical tests were twotailed and $\mathrm{P}<0.05$ was considered statistically significant.

\section{Author contributions}

Fang Cao and Wei Han conceived and designed the study. Fang Cao, Cong Zhang and Wei Han wrote the main manuscript text. Fang Cao and Cong Zhang are co-first authors. All authors contributed to the preparation of all tables and figures. All authors reviewed the manuscript and approved the submission.

\section{CONFLICTS OF INTEREST}

In this article, no financial support or relationships may pose conflict of interest by disclosing at the time of submission.

\section{REFERENCES}

1. Siegel RL, Miller KD, Jemal A. Cancer statistics, 2015. CA Cancer J Clin. 2015; 65:5-29.

2. Ng L, Poon RT, Pang R. Biomarkers for predicting future metastasis of human gastrointestinal tumors. Cell Mol Life Sci. 2013; 70:3631-56.
3. Hari DM, Leung AM, Lee JH, Sim MS, Vuong B, Chiu CG, Bilchik AJ. AJCC Cancer Staging Manual 7th edition criteria for colon cancer: do the complex modifications improve prognostic assessment? J Am Coll Surg. 2013; 217:181-90.

4. Nicholson KM, Anderson NG. The protein kinase B/Akt signalling pathway in human malignancy. Cell Signal. 2002; 14:381-95.

5. Xue G, Hemmings BA. PKB/Akt-dependent regulation of cell motility. J Natl Cancer Inst. 2013; 105:393-404.

6. Al-Bazz YO, Underwood JC, Brown BL, Dobson PR. Prognostic significance of Akt, phospho-Akt and BAD expression in primary breast cancer. Eur J Cancer. 2009; 45:694-704.

7. Yang ZY, Di MY, Yuan JQ, Shen WX, Zheng DY, Chen JZ, Mao C, Tang JL. The prognostic value of phosphorylated Akt in breast cancer: a systematic review. Sci Rep. 2015; 5:7758.

8. Yang Y, Luo J, Zhai X, Fu Z, Tang Z, Liu L, Chen M, Zhu Y. Prognostic value of phospho-Akt in patients with nonsmall cell lung carcinoma: a meta-analysis. Int J Cancer. 2014; 135:1417-24.

9. Qiu ZX, Zhang K, Qiu XS, Zhou M, Li WM. The prognostic value of phosphorylated AKT expression in non-small cell lung cancer: a meta-analysis. PLoS One. 2013; 8:e81451.

10. Tian WY, Chen WC, Li R, Liu L. Markers CD40, VEGF, AKT, PI3K, and S100 correlate with tumor stage in gastric cancer. Onkologie. 2013; 36:26-31.

11. Deng WF, Han J, Wang XH, Lin YJ, Zhang HY. Expressions and clinical significance of HER-3 and Akt in gastric cancer tissues. Chin J Cancer Prev Treat. 2010; 17:1935-8.

12. Liu MR, Wang WB. Expressions of ERCC1 and AKT1 in gastric cancer tissues and pericarcinoma tissues and their clinical significance. J Shandong Univ (Health Sci). 2010; 48:86-90.

13. Zou SJ, Chen ZF, Li M, Ji R, Lu H, Guo QH, Zhang ZY, Wang JX, Ren TW, Zhang LH, Zhao Y, Zhou YN. Expression of PI3K and AKT2 in gastric cancer and its relationship with clinicopathological features and survival of patients. J Pract Oncol. 2011; 26:346-50.

14. Bian YH, Wang ZS, Xu J, Zhao W, Cao H, Zhang Z. Elevated Rictor expression is associated with tumor progression and poor prognosis in patients with gastric cancer. Biochem Biophys Res Commun. 2015; 464:534-40.

15. Chang H, Jung WY, Kang YR, Lee H, Kim A, Kim BH. Expression of ROR1, p-Akt, and pCREB in gastric adenocarcinoma. Ann Diagn Pathol. 2015; 19:330-4.

16. Cinti C, Vindigni C, Zamparelli A, La Sala D, Epistolato MC, Marrelli D, Cevenini G, Tosi P. Activated Akt as an indicator of prognosis in gastric cancer. Virchows Arch. 2008; 453:449-55.

17. Han X, Shi Y, Dai GH. Expression of p-Akt-1 and clinical significance in gastric carcinoma. Chin Clin Oncol. 2011; 16:526-9. 
18. Kobayashi I, Semba S, Matsuda Y, Kuroda Y, Yokozaki H. Significance of Akt phosphorylation on tumor growth and vascular endothelial growth factor expression in human gastric carcinoma. Pathobiology. 2006; 73:8-17.

19. Liang M, Shi B, Liu J, He L, Yi G, Zhou L, Yu G, Zhou $\mathrm{X}$. Downregulation of miR203 induces overexpression of PIK3CA and predicts poor prognosis of gastric cancer patients. Drug Des Devel Ther. 2015; 9:3607-16.

20. Luber B, Deplazes J, Keller G, Walch A, Rauser S, Eichmann M, Langer R, Höfler H, Hegewisch-Becker S, Folprecht G, Wöll E, Decker T, Endlicher E, et al. Biomarker analysis of cetuximab plus oxaliplatin/ leucovorin/5-fluorouracil in first-line metastatic gastric and oesophago-gastric junction cancer: results from a phase II trial of the Arbeitsgemeinschaft Internistische Onkologie (AIO). BMC Cancer. 2011;11:509.

21. Murakami D, Tsujitani S, Osaki T, Saito H, Katano K, Tatebe S, Ikeguchi M. Expression of phosphorylated Akt (p-Akt) in gastric carcinoma predicts prognosis and efficacy of chemotherapy. Gastric Cancer. 2007; 10:45-51.

22. Murayama T, Inokuchi M, Takagi Y, Yamada H, Kojima K, Kumagai J, Kawano T, Sugihara K. Relation between outcomes and localisation of $\mathrm{p}$-mTOR expression in gastric cancer. Br J Cancer. 2009; 100:782-8.

23. Nam SY, Lee HS, Jung GA, Choi J, Cho SJ, Kim MK, Kim $\mathrm{WH}$, Lee BL. Akt/PKB activation in gastric carcinomas correlates with clinicopathologic variables and prognosis. APMIS. 2003; 111:1105-13.

24. Sasaki T, Kuniyasu H, Luo Y, Kitayoshi M, Tanabe E, Kato D, Shinya S, Fujii K, Ohmori H, Yamashita Y. AKT activation and telomerase reverse transcriptase expression are concurrently associated with prognosis of gastric cancer. Pathobiology. 2014; 81:36-41.

25. Sukawa Y, Yamamoto H, Nosho K, Kunimoto H, Suzuki H, Adachi Y, Nakazawa M, Nobuoka T, Kawayama M, Mikami M, Matsuno T, Hasegawa T, Hirata K, et al. Alterations in the human epidermal growth factor receptor 2-phosphatidylinositol 3-kinase-v-Akt pathway in gastric cancer. World J Gastroenterol. 2012; 18:6577-86.

26. Xue P, Zhou F, Li N, Li M, Wang LW. Clinical significance of the expressions of PTEN and p-Akt proteins in gastric carcinoma and its relationship to prognosis. Tumor. 2012; 32:281-5.

27. Hisamatsu Y, Oki E, Otsu H, Ando K, Saeki H, Tokunaga E, Aishima S, Morita M, Oda Y, Maehara Y. Effect of EGFR and p-Akt overexpression on chromosomal instability in gastric cancer. Ann Surg Oncol. 2016; 23:1986-92.

28. Courtney KD, Corcoran RB, Engelman JA. The PI3K pathway as drug target in human cancer. J Clin Oncol. 2010; 28:1075-83.

29. Engelman JA. Targeting PI3K signaling in cancer: opportunities, challenges and limitations. Nat Rev Cancer. 2009; 9:550-62.
30. Ocana A, Vera-Badillo F, Al-Mubarak M, Templeton AJ, Corrales-Sanchez V, Diez-Gonzalez L, Cuenca-Lopez MD, Seruga B, Pandiella A, Amir E. Activation of the $\mathrm{PI} 3 \mathrm{~K} / \mathrm{mTOR} / \mathrm{AKT}$ pathway and survival in solid tumors: systematic review and meta-analysis. PLoS One. 2014 Apr 28; 9:e95219.

31. Zhang J, Wang P, Zhu J, Wang W, Yin J, Zhang C, Chen Z, Sun L, Wan Y, Wang X, Chen G, Liu Y. SPARC expression is negatively correlated with clinicopathological factors of gastric cancer and inhibits malignancy of gastric cancer cells. Oncol Rep. 2014; 31:2312-20.

32. Zhong J, Chen S, Xue M, Du Q, Cai J, Jin H, Si J, Wang L. ZIC1 modulates cell-cycle distributions and cell migration through regulation of sonic hedgehog, PI(3)K and MAPK signaling pathways in gastric cancer. BMC Cancer. 2012; 12:290.

33. Gao C, Lu Y. [Correlation of multiple gene changes with malignant phenotype of human gastric carcinoma]. [Article in Chinese]. Zhonghua Yi Xue Za Zhi. 1996; 76:671-5.

34. Han W, Cao F, Chen MB, Lu RZ, Wang HB, Yu M, Shi CT, Ding HZ. Prognostic value of SPARC in patients with pancreatic cancer: a systematic review and meta-analysis. PLoS One. 2016; 11:e0145803.

35. Wang YY, Jiang JX, Ma H, Han J, Sun ZY, Liu ZM, Xu ZG. Role of ZIC1 methylation in hepatocellular carcinoma and its clinical significance. Tumour Biol. 2014; 35:7429-33.

36. McCorkle JR, Leonard MK, Kraner SD, Blalock EM, Ma D, Zimmer SG, Kaetzel DM. The metastasis suppressor NME1 regulates expression of genes linked to metastasis and patient outcome in melanoma and breast carcinoma. Cancer Genomics Proteomics. 2014; 11:175-94.

37. Shin JY, Kim JO, Lee SK, Chae HS, Kang JH. LY294002 may overcome 5-FU resistance via down-regulation of activated p-Akt in Epstein-Barr virus-positive gastric cancer cells. BMC Cancer. 2010; 10:425.

38. Tierney JF, Stewart LA, Ghersi D, Burdett S, Sydes MR. Practical methods for incorporating summary time-to-event data into meta-analysis. Trials. 2007; 8:16.

39. Stang A. Critical evaluation of the Newcastle-Ottawa scale for the assessment of the quality of nonrandomized studies in meta-analyses. Eur J Epidemiol. 2010; 25:603-5.

40. Wong WC, Cheung CS, Hart GJ. Development of a quality assessment tool for systematic reviews of observational studies (QATSO) of HIV prevalence in men having sex with men and associated risk behaviours. Emerg Themes Epidemiol. 2008; 5:23.

41. Egger M, Davey Smith G, Schneider M, Minder C. Bias in meta-analysis detected by a simple, graphical test. BMJ. 1997; 315:629-34. 